\title{
Las dificultades para construir el Estado nacional en el Perú. Desde la independencia hasta la república aristocrática (1821-1900)
}

\author{
Osmar Gonzales*
}

\section{Resumen}

En el presente artículo, el autor realiza. una lectura que indaga en las condiciones que retrasaron la formación del Estado nacional peruano desde el tiempo de la posindependencia (1821-1824) hasta el inicio de la república oligárquica en 18941895. Al mismo tiempo, se analiza críticamente la literatura que ha tratado dicho periodo, discutiendo brevemente algunas afirmaciones muy comunes en las ciencias sociales respecto al Estado oligárquico peruano.

\begin{abstract}
In the present article, the author makes a reading that search the conditions that delayed the peruvian national State formation from the post independence (18211824) time to the beginning of the oligarchic republic in 1894-1895. At the same time, the literature about this period is analyzed critically discussing some affirmations very common in social sciences with respect to the peruvian oligarchic State.
\end{abstract}

Palabras clave:

Estado, nación, Perú, oligarquía, clase dirigente.
Fecha de recepción: febrero de 2000

Fecha de aceptación: abril de 2000

* Sociólogo peruano, doctor en Ciencias Sociales por el Centro de Estudios Sociológicos de El Colegio de México. Correo electrónico: ogonzalesa@conacyt.mx 
$\mathbf{M}$ i objetivo en este artículo es analizar la formación del Estado peruano desde una lectura que atienda tanto los procesos de largo plazo, como los cambios específicos que se producen en distintas etapas históricas; por ello discurre desde el tiempo de la posindependencia hasta el inicio de la república oligárquica en 1894-1895, indagando las condiciones histórico-sociales que retrasaron la formación de un Estado nacional. Lue. go de mostrar un breve panorama de la discusión sobre el Estado peruano, se analizan los cambios que ocurren en el ámbito de las elites que lo controlan y sus contradicciones, siguiendo a la vez las transformaciones que se producen en los diferentes sectores de las clases populares. Finalmente, se discuten brevemente algunas afirmaciones muy comunes en las ciencias sociales respecto al Estado oligárquico peruano.

\section{EL ESTADO PERUANO: UN OGRO INÚTIL}

Es importante iniciar el análisis del proceso formativo del Estado peruano en el tiempo de la independencia (18211824), porque ayuda a situar en una perspectiva histórica la aparición del populismo, y evita entender éste como un hecho que careció de antecedentes, o como una etapa que cancela, sin más, a las anteriores.

Haber comprendido el proceso histórico de formación del Estado peruano como un continuum, ha conducido a privilegiar las permanencias que efectivamente existieron, y a menospreciar las modificaciones que orientan un tipo de lectura que podemos llamar organicista. ${ }^{1}$ En sentido contrario, leer la historia como una sucesión de etapas, ha sesgado la lectura haciendo predominar la sucesión de hechos y atendiendo a lo contingente, sin considerar lo heredado. ${ }^{2}$ Sin embargo, más allá de la fuerte carga ideológica con que están teñidas las polémicas sobre el Estado en el Perú, ${ }^{3}$ existe una idea más o menos aceptada en las ciencias sociales peruanas: considerarlo como una institución inútil.

Tanto liberales como marxistas coinciden en señalar que el Estado siempre ha estado alejado de la sociedad "real". Los primeros atribuyen este alejamiento a su característica mercantilista, es decir, a la de operar al servicio de unos pocos privilegiados que utilizan al Estado como medio de enriquecimiento; ${ }^{4}$ mientras que los segundos le objetan su carácter clasista y su subordinación a intereses económicos internacionales que le impiden cumplir funciones de

\footnotetext{
${ }^{1}$ Según Julio Cotler, por ejemplo, el proceso seguido por el Estado peruano es particular en América Latina por la fuerte presencia de lo que denomina "la herencia colonial". Ésta tiene dos consecuencias. Primero, prefigura el carácter dependiente del Perú respecto del capitalismo hegemónico y, segundo, preserva las "relaciones coloniales" en la explotación de la mayoritaria población indígena. Ambos elementos impidieron una integración plena de la sociedad al generar la marginación tanto social como étnica, e impidieron, además, un desarrollo autónomo de los poderes internacionales. La consecuencia es que en el Perú no se puede hablar de hegemonía de una clase dirigente. Cotler, Clases, 1978 , p. 388.

${ }^{2}$ Ver, por ejemplo, Chirinos, Historia, 1977.

${ }^{3}$ Whitehead, "Algunas", 1990.

${ }^{4}$ Ver especialmente Soto, Otro, 1986.
} 
carácter nacional. En definitiva, el Estado en el Perú nunca ha sido representativo de la sociedad. Más aún, lo ha caracterizado su fuerza coaccionadora utilizada, precisamente, para sustituir esa incapacidad de representación. Sin embargo, esta crítica -la de la falta de reconocimiento de la sociedad al Estado- no es novedosa, pues hay antecedentes de ella en las reflexiones de pensadores $\tan$ importantes y distintos teórica e ideológicamente, como Víctor Andrés Belaúnde ${ }^{5}$ y Jorge Basadre. ${ }^{6}$

Otro punto más o menos coincidente es que el Estado moderno empezó a constituirse en el Perú durante el gobierno de Nicolás de Piérola, luego de la derrota del general Andrés Avelino Cáceres en la guerra civil de $1894{ }^{7}$

Como intento mostrar en las siguientes páginas, la formación del Estado peruano -y en general, de cualquier Estado- no es inteligible si no se recurre a la lectura histórica, la cual debe evitar dos peligros: la concepción cíclica que entiende que todo se repite pero con nuevos actores (con lo cual, se negaría todo lugar a lo imprevisto), y la visión romántica que supone que todo tiempo pasado fue mejor. Evitando en lo posible ambos riesgos y teniendo como objetivo realizar una lectura crítica de

${ }^{5}$ Belaúnde, Crisis, 1994.

${ }^{6}$ Basadre, Perú, 1978.

${ }^{7}$ Sin embargo, algunos autores sostienen que la consolidación del Estado apenas empieza a producirse durante el oncenio de Augusto B. Leguía (1919-1930), otros afirman que ello ocurre en el tiempo del reformismo militar del general Juan Velasco Alvarado (1968-1975), otros más señalan que eso apenas se está produciendo durante el gobierno de Alberto Fujimori (desde 1990). los hechos, uno puede llegar a formarse una idea más cabal del proceso histórico y entender, simultáneamente, lo nuevo y lo constante.

DE LA INDEPENDENCIA A IA GUERRA DEL PACÍFICO

En el Perú, la separación política de la corona española fue conseguida en contra de la elite rentista limeña, cuyo fidelismo a la misma se explica dado que las fuentes de su poder económico y político se basaban en los privilegios extraídos de su estrecha relación con la metrópoli, especialmente por medio de su participación en el Tribunal del Consulado. Esa lealtad de la elite limeña con la corona explica por qué el Perú fue la última colonia de América del Sur en lograr la independencia. Dicho sentimiento contrastaba con las aspiraciones separatistas de las elites criollas de Caracas, Santiago y Buenos Aires, mismas que se habían beneficiado con las reformas liberales borbónicas y con el nuevo comercio internacional. Debido a éste, en dichas ciudades surgieron pujantes burguesías comerciales para las cuales resultaba contraproducente mantenerse bajo el dominio español. Liquidado el monopolio comercial de España en 1778, estas burguesías obtenían sus mayores ingresos del comercio con Inglaterra y Holanda.

Ante el fidelismo de la elite limeña, los ejércitos de San Martín y Bolívar debieron ocupar el territorio peruano para declarar definitivamente la independencia de los países sudamericanos. Por este hecho, autores como 


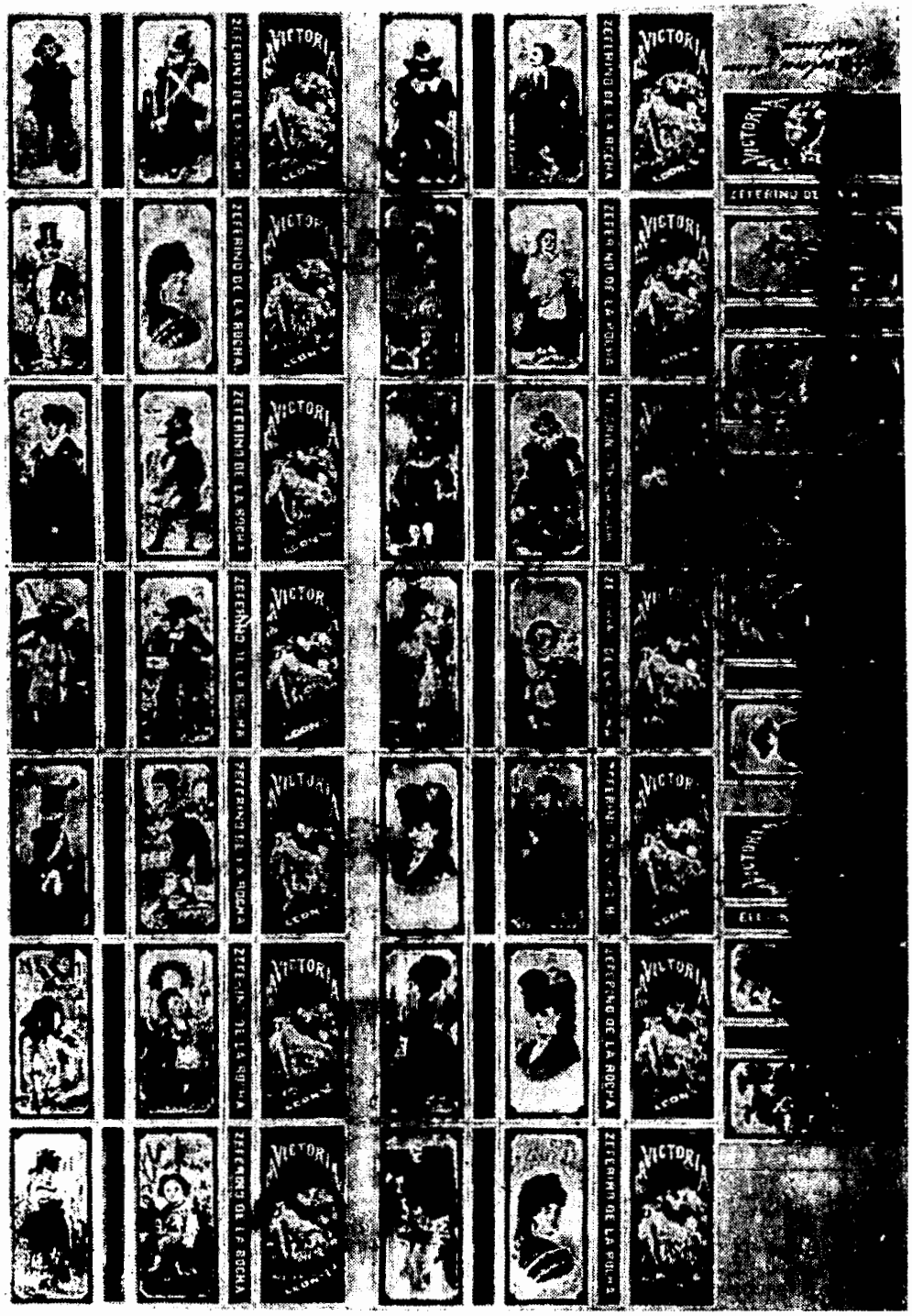


Heraclio Bonilla señalan que la independencia peruana no fue conquistada, sino otorgada. ${ }^{8}$ Sin embargo, esta tesis admite matices, pues existen evidencias de que ciertos sectores sociales peruanos participaron activamente en la guerra separatista: ${ }^{9}$

Lo cierto es que en este proceso [independentista] se dieron comportamientos muy diferenciados de uno y otro sector social, como lo muestra la oposición polar entre la opción realista de la burguesía mercantil limeña, agrupada en el Tribunal del Consulado, y el masivo concurso de los indígenas organizados en guerrillas y montoneras, en la sierra central. ${ }^{10}$

En este punto es importante señalar dos aspectos. En primer lugar, la participación indígena en las guerrillas y montoneras rebeldes se limitó a aquellas zonas donde la explotación servil no era significativa (sierra central, básicamente). Pero también hubo sectores indígenas que optaron por el bando fidelista. De esta manera, el contingente indígena fue el que soportó el peso de la guerra, pues participó tanto en el ejército realista como en el libertador, colaborando en proyectos que no le eran propios al actuar bajo el mando de los sectores criollos y mestizos. La posibilidad de un proyecto indígena había quedado liquidada en 1781 con la derrota de la rebelión de Túpac Amaru en el Cuzco. En segundo lugar, la

\footnotetext{
${ }^{8}$ Bonilla y Spalding, Independencia, 1971.

${ }^{9}$ Ver la réplica a la tesis de Bonilla realizada por Basadre, Azar, 1973. También O'Phelan', "Mito", 1987.

10 Manrique, Historia, 1995, p. 31.
}

fragmentación de las elites criollas peruanas, explicable por sus diferentes anclajes económicos, regionales o locales, impidió la formación de un Estado central, convirtiéndose por ello el territorio peruano en un escenario de pugnas entre caudillos militares. ${ }^{11}$

Luego de la separación de España y fundado formalmente el Estado peruano, Simón Bolívar, al implantar en el Perú la Dictadura Vitalicia (1823-1826), se propuso formar un Estado fuerte y centralizado, sostenido por propietarios individuales. Dicho proyecto produjo dos consecuencias distintas. Por un lado, atentó contra los intereses de los poderes regionales y locales. Como consecuencia, éstos se opusieron decididamente a los decretos bolivarianos porque los percibían como destinados a acabar con las formas productivas tradicionales basadas en la mano de obra indígena de la que eran directos beneficiarios. Pero, por otro, la idea de Bolívar de convertir a los campesinos indígenas (fuertemente arraigados en una organización comunal) en propietarios individuales, dejó a éstos indefensos frente a la arremetida de las elites criollas que aprovecharon el "reparto de tierras" en beneficio propio profundizando el sistema de servidumbre. $^{12}$

${ }^{11}$ Esta fragmentación explica en parte que el hecho de la independencia no sea considerado como un momento fundante en la historia de la república peruana, un momento simbólico en el cual todos los peruanos puedan sentirse identificados e integrantes de una colectividad. Al respecto es muy sugerente el artículo de Remy, "Historia", 1995.

12 Bolívar fue un tenaz opositor del mantenimiento de los privilegios indígenas, por eso, 
Expulsado Bolívar del Perú en el año de 1826, las luchas entre caudillos militares y el estado de guerra subsecuente impidieron constituir un poder central legitimado. Los criollos que sucedieron a los españoles en los asuntos de gobierno fueron hacendados que no tenían mayor poder que el regional o local. En otras palabras, no se conformó un poder de alcance nacional durante este periodo temprano de formación del Estado. Destruidas las instituciones coloniales, el esfuerzo requerido para construir al Estado peruano iba más allá de la capacidad de los pequeños poderes. Sólo instituciones como la Iglesia y el ejército permanecieron en el panorama político y social de la nueva república. Los caudillos militares, que controlaban el Estado, actuaron como una fuerza supletoria de una clase dominante insuficientemente organizada y consolidada para afrontar funciones directrices. El panorama del momento era bastante desolador: Estado pobre (en 1822 ya debía 1200000 libras esterlinas), instituciones débiles, clase propietaria sin atributos de conductora, y sociedad fragmentada por motivos económicos, raciales y sociales. Bajo estas condiciones nació el Perú como país independiente.

El proyecto más serio para crear un Estado a inicios del siglo XIX fue el di-

cuando llegó al Cuzco en 1825 abolió todos los títulos nobiliarios prehispánicos. Como señala Mark Thurner, "Bolivar no andaba buscando un inca": "Without any usable past, then, Creole republicanism would largely look the future (and thus to artifice of modernism) as the wellspring of Latin American nationhood -and not, as much as was possible, to the Iberian or Andean past." Thurner, Republics, 1977, p. 10. rigido por Andrés Santa Cruz, quien pretendió unir bajo una sola autoridad a los territorios del Alto (Bolivia) y Bajo Perú en forma de una Confederación (1836-1838). Frente a tal proyecto, los caudillos limeños y norteños temieron que su posición de privilegio pudiera sufrir mengua ante los propietarios bolivianos, más liberales en materia económica (merced a su relación beneficiosa con Inglaterra) y articulados a los poderes regionales del sur peruano. La derrota en 1838 de la Confederación peruano-boliviana cerró la oportunidad de crear un Estado sólido y reequilibrar el juego de poderes entre las elites norteñas y limeñas, por un lado, y las sureñas, por el otro.

La derrota del proyecto de Santa Cruz fortaleció a la elite limeña en un panorama que favorecía la autonomía de los poderes locales. Éstos organizaban ejércitos propios, entraban en guerra entre sí, y establecían alianzas espurias y efimeras. ${ }^{13} \mathrm{La}$ base del poder económico de los poderes locales estaba dada, sobre todo, por la cantidad de mano de obra indígena de la que disponían. Este archipiélago en que se ha-

13 "De esta manera, la reestructuración de la sociedad siguió la suerte de los caudillos, de sus éxitos y fracasos en relación a otros caudillos y a las varias oligarquías. Pero la incapacidad de aquéllos de afirmar su dominio personal motivó, a su vez, la continua mudanza de clientelas en su afán de mantener o conseguir las prebendas políticas que, al igual que en el virreinato, les permitían explotar colonialmente a la población dominada y enriquecerse. Este continuo desplazamiento no era casual: la relación de clientela entre caudillo y allegados reposaba en el respaldo de sus seguidores en la medida que éste fuera capaz de otorgarles favores personales. Cotler, Clases, 1978, p. 74. 
bía convertido el Perú, hacía más dificultoso aún el proceso de formación de un Estado nacional, al mismo tiempo que impedía entender el decurso histórico peruano como un todo homogéneo. En el territorio peruano coexistían ciclos económicos regionales diversos que no se correspondían. La crisis de una zona podía ser contemporánea de un periodo de auge de otra. En el plano social, estas diferencias de ritmos explican por qué no se produjo un movimiento indígena articulado en el ámbito nacional, pues las rebeliones sólo aparecían en aquellas regiones que experimentaban crisis.

La crisis fiscal en que se había sumergido el Estado peruano luego de la guerra de Independencia obligó a los sucesivos gobiernos a restituir el tributo, una institución colonial que en la república se denominó "contribución personal". El sector indígena era sumamente importante por dos cosas. Primero, por ser la población mayoritaria del Perú: en 1876, de 1500000 habitantes, los indios constituían el $62 \%{ }^{14}$ Segundo, porque la importancia demográfica se sumaba al hecho económico, pues el grueso de los contribuyentes estaba compuesto por indígenas, especialmente en los departamentos del sur andino, como Cuzco y Puno.

El pago del tributo indígena sustentaba la transferencia del excedente económico al gobierno, como lo demuestran las cifras. Entre 1826 y 1854, el Estado recibió por concepto del tributo indígena aproximadamente 1300000

${ }^{14}$ Gootenberg, "Población", 1995. pesos, suma equivalente a la tercera parte del ingreso público. ${ }^{15}$

Desde los años 1840, el boom del guano permitió la introducción de circulante, con lo cual la contribución indígena pasó a un segundo plano. Por ello, Ramón Castilla la abolió en 1854, siendo restituida en 1876, cuando los sueños alentados por la exportación de guano se habían esfumado. ${ }^{16}$

La época del comercio guanero -iniciada en los años 1840 , y que concluyó en los 1870-, fue central en la conformación y desventura del Estado peruano y de sus elites. Su historia es importante. En relación con el aspecto económico, la comercialización de dicha riqueza natural significó el abandono del modelo proteccionista, característi-

${ }^{15}$ Políticamente, las relaciones que estableció el Estado con la población indígena tendrian sus repercusiones en la configuración que adquirió el Estado republicano, pues azuzaron los conflictos intercaudillos y la fragmentación, como lo señala Heraclio Bonilla: " $[\ldots]$ durante gran parte del siglo $\mathrm{XIX}$, la vinculación política entre el Estado y la masa campesina consistió en una relación asimétrica de drenaje de exce. dentes económicos y de recursos humanos para sostener las continuas pugnas de los caudillos y caciques locales. Esta vinculación, además, estuvo mediada por los representantes regionales del Estado, quienes en algunos casos terminaron por apropiarse de una parte de este excedente y, dada la distancia y la fragilidad del gobierno central, terminaron fragmentando al Estado para llegar a constituir, con el apoyo y la alianza de los poderosos locales, un conjunto de microsistemas políticos divorciados entre sí." Bonilla, "Estado", 1989, p. 26.

${ }^{16}$ La historia del tributo indigena está llena de vaivenes, expresivos de las incertidumbres criollas respecto a su relación con la población mayoritaria indígena. Es así que San Martín lo canceló en 1821, pero fue restituido en 1826 , hasta llegar al gobierno de Castilla. 


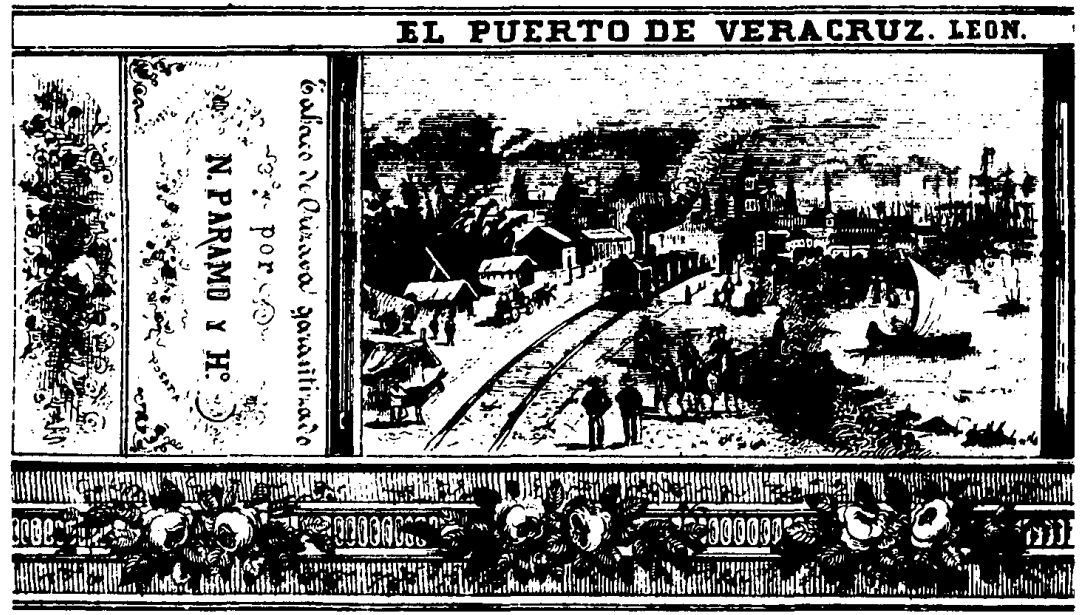

co después de lograda la independencia de España, y la adopción del modelo liberal ligado al mercado internacional. ${ }^{17}$ En un primer momento, las rentas producidas por el guano fueron percibidas por comerciantes extranjeros, pero en 1850 pasaron a manos del sector privado peruano por medio de la "consolidación de la deuda nacional". Ésta no fue otra cosa, por parte del Estado que honrar a aquellos que habían apoyado financieramente la guerra de independencia. La consolidación fue un gran negocio para quienes controlaban el poder y sus allegados, y se prestó a una gran corrupción. ${ }^{18}$ Los consigna-

${ }^{17}$ Gootenberg, Caudillos, 1997.

${ }^{18}$ Como señala Alfonso W. Quiroz: "Sólo aquellos hacendados y rentistas que dinamizaron sus propiedades ligando los productos que obtenian de ellas a la esfera comercial, y estableciendo importantes vínculos con grandes co- tarios elevaron impunemente los intereses de sus bonos frente al Estado, contando con la complicidad de un gobierno corrupto, como fue el de José Rufino Echenique (1851-1854). Como señala Dennis L. Gilbert:

La deuda interna del Perú ascendió de 4000000 de pesos a 23000000 de pesos en unos cuantos años [...] Muchos de los amigos del régimen fueron doblemente favorecidos al ser sus bonos redimidos por el gobierno, el que a su vez vendió bonos en el mercado internacional que debían ser servidos con las rentas del guano. Por lo tanto, la deuda interna fue convertida en deuda externa para beneficio de una minoría relativamente pequeña. ${ }^{19}$

merciantes de Lima, lograron garantizar su participación exitosa en la consolidación." Quiroz, Deuda, 1987, p. 201.

${ }^{19}$ Gilbert, Oligarquía, 1982, p. 18 
Las familias que se beneficiaron con el comercio guanero constituyen el punto de origen de lo que después se conocería como la oligarquía peruana. Pero trajo, además, otras consecuencias: la formación de un gobierno fuerte en Lima; la posibilidad de mantener una burocracia considerable para la época, y un ejército numeroso y profesional, y el cambio en las relaciones entre Lima y las provincias, haciendo posible que aquélla ya no dependiera de éstas. Además, este momento marcó el inicio de una de las características fundamentales del desarrollo político peruano: la centralización del poder político en los gobiernos limeños apoyados en la economía exportadora costeña y dominados por los intereses exportadores. ${ }^{20}$ Otra consecuencia importante fue la conformación, en 1871, del Partido Civil por parte de la plutocracia guanera.

Entre 1850 y 1879 se presentaron los primeros intentos de control empresarial sobre los recursos ubicados en la explotación del guano y la del salitre. Pero los empresarios que se beneficiaron con el control del comercio guanero se tuvieron que enfrentar al avance del capital extranjero, respondiendo a ello con una acumulación de capital, movilizando sus bienes inactivos y reactivando las plantaciones cañeras respaldadas por el Estado, pues éste había financiado la manumisión de esclavos. ${ }^{21} \mathrm{~A}$ ello se sumó el tendido ferroviario, también financiado por

${ }^{20}$ Ibid., p. 19.

${ }^{21} \mathrm{La}$ liberación de 20000 esclavos negros significó al fisco un egreso de 6000000 de pesos que fueron a parar a propietarios priva- el Estado, y ejecutado por contratistas extranjeros. En otras palabras, hubo pugna entre el capital nativo y el extranjero por el control de los recursos, y no simple arrasamiento de éste sobre aquél. La conclusión fue la fusión de viejos y nuevos intereses en los bancos comerciales e hipotecarios para facilitar el paso de fondos al sector agrícola y salitrero. La guerra de 1879 sobrevino en pleno despliegue de esta estrategia económico-financiera. Uno de sus resultados más nefastos fue el de truncar

una transformación potencialmente más moderna en la comprensión de la elite peruana [retardando] una mayor coordinación nativa y la diversificación de las instituciones de crédito a largo plazo. ${ }^{22}$

Aparte de los pingües ingresos que significó para el Estado peruano la comercialización de la riqueza guanera, ésta fue fundamental para explicar el enorme endeudamiento externo que aquél contrajo bajo la garantía del recurso natural. Las cifras son sumamente elocuentes (véase cuadro 1).

El Estado endeudado atravesó una época de fraude y corrupción. El préstamo de 11920000 pesos suscrito en 1870 fue destinado a financiar la política ferrocarrilera impulsada por el presidente José Balta (1868-1872). Para entonces, su ministro de Hacienda, Nicolás de Piérola, había despojado del control del comercio guanero a los consignatarios nacionales para entregárselo al agente francés Auguste Dreyfus.

dos, quienes luego reinvirtieron en las haciendas de caña de azúcar.

${ }^{22}$ Quiroz, "Grupos", 1986, p. 13. 
Esta medida llevó al primero de los muchos enfrentamientos que Piérola tendría con la plutocracia limeña.

En 1876 el Estado se declaró en bancarrota, pues no supo utilizar productivamente los ingresos generados por el comercio del guano. De ellos, sólo una pequeña porción fue destinada a gastos productivos, como la construcción de ferrocarriles (20\%). El resto, a la burocracia civil y militar (54.5\%), al pago de deudas (19.5\%) y una pequeña porción (7\%) al gasto social. Como concluye Alfonso Quiroz:

En sintesis: el fin de la era del guano dejó una deuda externa acumulada de 35000000 de libras esterlinas cuya amortización demandaba 2500000 libras anuales que equivalían a la totalidad del presupuesto nacional, y que no habia de dónde pagar. El Estado se había acostumbrado a depender del crédito externo y, en esas condiciones, entró el Perú en la gran crisis mundial de la economía capitalista primero $y$, pocos años después, a la guerra con Chile. ${ }^{23}$

Como se puede observar, en este primer momento de formación del Estado peruano se conjugaron varios elementos que actuaron como obstáculos para que se construyera un poder central. Primero, la ausencia de un sector político con capacidad suficiente para subordinar a los contendientes y, desde esa posición, ir formando instituciones. El control estatal fue visto como un botín de particulares. En segundo lugar, muy relacionado con lo anterior,

${ }^{23}$ Ibid., p. 126. el usufructo de las riquezas naturales (entonces propiedad del Estado) y las redes privadas que se construyeron alrededor de su comercio, impidieron un proceso de acumulación a escala nacional en donde se articularan diferentes regiones a un proyecto capitalista. Tal fue el caso de la plutocracia guanera, cuyos ingresos, si bien tuvieron ciertos efectos en la economía peruana, no fueron lo suficientemente poderosos para llegar a incorporar a las regiones más lejanas con respecto a la costa y la capital, principalmente. Por el contrario, se conformaron elites de poder regional con débil articulación entre sí.

En tercer lugar, los prejuicios raciales marginaban del Estado y del sentido de comunidad a la mayoría de la población, compuesta por indígenas. Éstos sólo fueron tomados en cuenta a la hora de las guerras entre caudillos, para las faenas agrícolas y mineras o para rendir tributos. El contingente indígena siempre fue marginado de un concepto amplio de ciudadanía. Bajo estas condiciones era muy difícil que el Estado peruano adquiriera alcance nacional.

De la guerra Del PaCífico a la REPÚBLICA ARISTOCRÁTICA

La guerra del Pacífico (1879-1883) entre Perú y Chile, también llamada "la guerra del guano y del salitre", ocurrió justamente cuando el declive del comercio guanero llegaba a su etapa final, y se buscaba un elemento sustituto, como el salitre hallado en la región sur del Perú y norte de Bolivia -impor- 
tante fertilizante demandado por Inglaterra para la expansión de su economía agrícola. Las elites chilenas, provechosamente relacionadas con el mercado exterior, expansivas y poderosas, necesitaban del recurso salitrero para proseguir con su desarrollo económico. EI Estado chileno declaró la guerra primero a Bolivia; luego, el Perú se vio involucrado en el conflicto, con base en un tratado de defensa mutua firmado con este país en 1873.

La guerra pondría de relieve las profundas escisiones del Perú. Las pugnas intraelites reaparecieron luego del vacío de poder ocasionado por el cuestionado viaje del presidente Mariano Ignacio Prado a Europa en 1879, supuestamente para acelerar el envío del armamento que había solicitado. En esas circunstancias, Piérola asumió ilegítimamente el poder; se autoproclamó dictador, y se recrudeció el conflicto iniciado con la plutocracia limeña cuando el Estado había arrebatado a los consignatarios del guano la comercialización de ese producto, encontrando esta vez apoyo entre las oligarquías provincianas. Estas alianzas, aynque provechosas políticamente para el caudillo, tuvieron consecuencias nefastas en el plano militar. Naturalmente, se produjo un profundo desconcierto. Al privilegiar Piérola su rivalidad con los civilistas $^{24}$ (al negarles abastecimiento y recursos a los batallones dirigidos por militares afines al civilismo), dejó prácticamente inermes ciertos puntos es-

\footnotetext{
${ }^{24}$ El Partido Civil, fundado en 1870 , fue una consecuencia directa del auge del comercio guanero. Dicho partido se convirtió en el eje político de la llamada república aristocrática.
}

tratégicos para la defensa del territorio peruano contra la invasión chilena. Sin lugar a dudas, la endeblez institucional y la fragmentación nacional se encuentran detrás de la derrota militar.

Las contradicciones sociales también salieron a flote, pues sectores sometidos a relaciones de esclavitud o servidumbre, como los chinos, los negros y los indígenas de ciertas regiones, vieron la oportunidad de liberarse de sus condiciones de explotación cuando el ejército chileno tocó tierra peruana.

Se hizo patente el temor de ciertas elites frente a una insurrección popular cuando solicitaron a las tropas chilenas que permanecieran en territorio peruano, alargando innecesariamente un conflicto que ya había sido resuelto en favor del país sureño. Salvo en la zona de la sierra central, los indígenas no se sintieron comprometidos con la defensa de un Estado que no percibían como suyo, y que no había hecho otra cosa que prolongar su situación de sojuzgados vivida desde la época colonial. La excepción fue la que protagonizó el general Cáceres, terrateniente de la sierra central, quien pudo comprometer exitosamente a sectores indígenas en la guerra contra el ejército chileno. Es importante mencionar que se trata de la misma zona donde se organizaron las guerrillas y montoneras de indígenas y mestizos que lucharon por la independencia del imperio español, lo cual es expresivo de la peculiaridad de la sierra central. ${ }^{25}$

25 "Económica y políticamente, la regiôn central estuvo integrada al desarrollo de Lima y de la costa, por lo menos desde inicios del siglo 


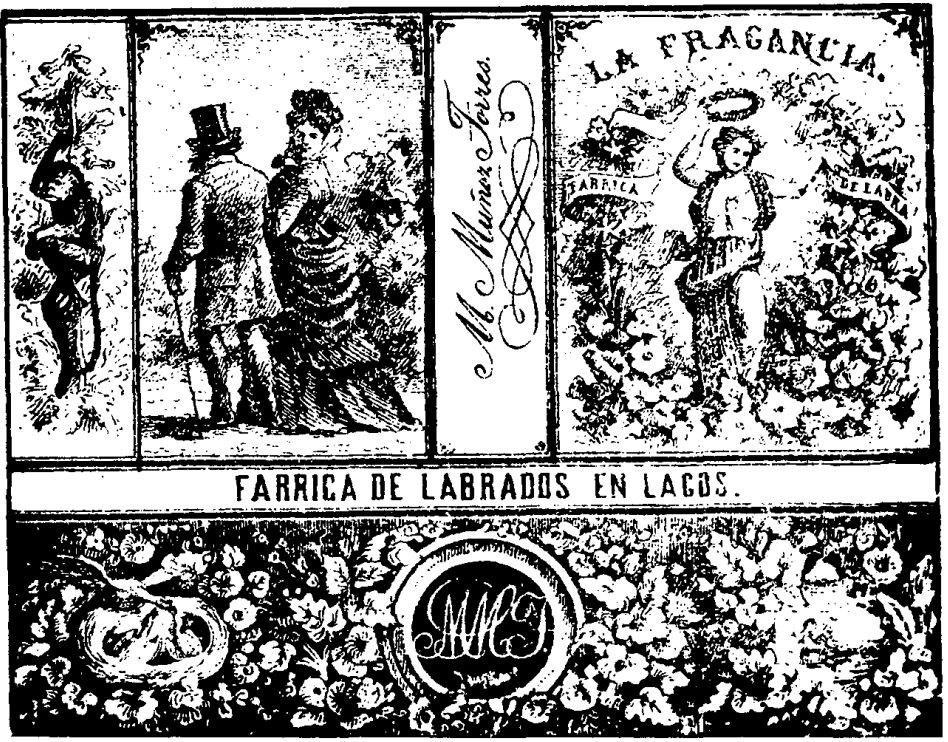

Los elementos señalados (pugnas entre las elites, contradicciones sociales y falta de integración nacional) pusieron en evidencia el problema de la precariedad del Estado peruano. La derrota militar del Perú hizo tomar conciencia en ciertas elites de que había que racionalizar al Estado. Ello implicaba, entre otras cosas, definir un territorio (cosa elemental pero esen-

XIX. Durante la guerra de Independencia, fue la única zona del virreinato que generó un esfuerzo guerrillero independiente de apoyo a los ejércitos de San Martín (1820-1822) y Bolívar (18231824) en sus intentos de liberar el territorio de la presencia española. Los mineros y comerciantes que encabezaron este esfuerzo, consolidaron más tarde su posición económica y política en la zona, comprando las mejores haciendas a una fracción de su precio original. Además de cial para afianzar un poder con pretensiones nacionales), y preguntarse acerca de quiénes deberían conformar la nacionalidad. En otras palabras, la precariedad nacional que evidenció la derrota, llevó a ciertos sectores de las elites a preguntarse sobre la manera de construir un Estado y una sociedad nacionales. Las reflexiones más explícitas apenas serían formuladas a comienzos

diversificar sus inversiones en la agricultura, la minería y el comercio, esta nueva clase dominante regional contrajo alianzas matrimoniales con importantes familias de otras zonas. Hacia la década de 1870 , sus miembros más prestigiosos habían participado directamente, o mediante el matrimonio, en la consolidación de la deuda interna, la organización de los primeros bancos, el contrato Dreyfus, y la fundación del Partido Civilista". Mallon, "Problema", 1981. 
del siglo $\mathrm{XX}^{26}$ Mientras tanto, una voz solitaria, la de Manuel González Prada, ${ }^{27}$ acusaría a las elites de la derrota ante Chile y afirmaría que el Perú sólo se constituiría en una nación cuando los habitantes de los Andes tomaran en sus manos el destino del país.

No hay Estado sin territorio, es decir, sin la delimitación de fronteras. Su demarcación es básica para establecer el poder del Estado. ${ }^{28}$ Precisamente, éste fue uno de los temas centrales presente en todos los gobiernos de la posguerra con Chile. Ello explica la continua atención de los gobiernos sucesivos a los acuerdos con los países fronterizos. En otras palabras, se trataba de la construcción urgente de la soberanía estatal.

El fracaso militar colocaría dos asuntos como centrales, a los cuales las elites debían responder. Primero, équiénes constituirían la nación?, ¿quiénes deberían integrarla?, ¿a quiénes se debería excluir? En suma, ¿a quiénes se debería reconocer como peruanos? Las soluciones ofrecidas eran complejas, pues tenían que elaborarse dentro de un clima de racismo prevaleciente en gran parte de las elites, las cuales proclamaban que los indígenas eran llamas parlantes o humanos que habían

\footnotetext{
${ }^{26}$ Sobre el proyecto de los intelectuales de principios de siglo ver Gonzales, Sanchos, 1996.

${ }^{27}$ Manuel González Prada (1844-1918) fue el más duro crítico que conoció la plutocracia civilista, especialmente después de la derrota en la guerra del Pacífico. Entre sus obras más famosas se pueden mencionar Horas de lucha, Pájinas libres, Bajo el oprobio, entre otras.

${ }^{28}$ Foreman-Peck, Historia, 1995, p. 4.
}

cerrado su ciclo de evolución. ${ }^{29}$ A lo más, algunos expresaban su deseo de que la sangre indígena fuera poco a poco eliminada vía el mestizaje y el cruce con las razas superiores (léase europeas) ${ }^{30}$

Un país empobrecido como el Perú no podía darse el lujo de prescindir de la mayoría de su población (las llamadas "razas de color"), tanto por su im. portancia como fuerza de trabajo como por ser sujetos que pueden rendir al Estado tributos o impuestos. Es precisamente en este punto donde aparece el segundo aspecto del problema de la ciudadanía. Un Estado central es tal en tanto es capaz de recabar impuestos legítimamente (y esto es el resultado de una larga historia que va desde la represión pura hasta el disciplinamiento de los ciudadanos), lo que implica la necesidad de que el Estado se racionalice.

La racionalización del Estado responde a una política expresa de una

${ }^{29}$ Alejandro O. Deustúa fue, quizá, el que más explícitamente proclamaba su racismo en un ambiente en el cual, según Gonzalo P'ortocarrero Maisch, luego de la derrota de la guerra de 1879, el racismo se ocultaba en los discursos públicos, aunque mantenía su vitalidad en las esferas de la vida cotidiana. Portocarrero, "Fundamento", 1995.

${ }^{30}$ Evidentemente, estas propuestas son parte de las ideas del momento en las cuales se trataban de unir la tesis de la supervivencia de las especies de los más aptos con los planteamientos racistas que atribuían a ciertas razas determinados papeles. En consecuencia, se afirmaba que habia ciertas razas que estaban llamadas a dirigir y dominar y otras a obedecer. De esta manera, se "naturalizaban" las diferencias sociales expandiendo la idea de que frente a ellas no había posibilidad de cambio por la acción de los hombres. 
clase o alianza de clases que busca darle dirección. Pero en el Perú, iacaso hubo una o más clases consolidadas económicamente y de alcance nacio. nal, con proyecto e ideología definidos, que se disputaran la hegemonía?, ¿o más bien se trató de pugnas entre personalidades fuertes, entre caudillos con cierto soporte social proveniente de sus respectivos poderes locales? Casi sin instituciones, los caudillos (militares o civiles) ejercían el papel de buenos y severos padres que debían disciplinar a sus súbditos, mientras éstos aprendian a vivir "civilizadamente". Con el fin de la guerra en 1883 lo que volvió, sin embargo, no fue la civilización, sino el militarismo.

Nuevamente el Perú se vio envuelto en enfrentamientos entre caudillos, especialmente entre Miguel Iglesias, terrateniente cajamarquino (norte del Perú) y Cáceres. Iglesias, luego de participar activamente en la guerra contra Chile, pactó con el gobierno sureño a cambio de protección ante los intentos de sublevación de los indígenas, y porque necesitaba además la presencia del ejército invasor para ganar tiempo y prepararse para su enfrentamiento por el poder con Cáceres. La guerra externa devino paulatinamente en guerra civil. Iglesias, que desconoció al gobierno instalado en Arequipa (sur del Perú), firmó la rendición con la consecuente pérdida de Arica y Tarapacá, las llamadas "provincias cautivas". Por su parte, según el acuerdo de ambos países, Tacna sería devuelta al Perú en un periodo de diez años, pero esto apenas se cumpliría en 1921.

En 1885, Cáceres consiguió derrotar a Iglesias y asumió la presidencia del Perú. Una vez en el gobierno, tuvo como principal preocupación recuperar las haciendas que habían quedado en manos de los guerrilleros indígenas del centro, quienes, durante la guerra con Chile, habían escarmentado, con el apoyo del propio Cáceres, a los propietarios colaboracionistas con el invasor. El Cáceres nacionalista dejó su lugar al Cáceres terrateniente. Por eso restituyó la contribución personal y creó las Juntas Departamentales, otorgando privilegios al poder local sobre el central. El Estado continuaba sin establecer relaciones de alcance nacional con una sociedad que, por su parte, mantenía las antiguas divisiones culturales, lingüísticas, regionales y sociales heredadas de la colonia.

En el plano económico, después de la guerra con Chile el Perú se sumergió en una profunda crisis económica y de endeudamiento, que sólo algunos años después comenzaría a revertirse. En ese contexto, entre 1884 y 1895 , cuantiosos recursos internos pasaron a manos de intereses foráneos. Las grandes compañías comerciales extranjeras (de importación y exportación) se convirtieron en acreedores de tal magnitud que podían imponer las reglas del juego económico. En consecuencia, el control comercial se decidió entre casas comerciales y los pocos bancos sobrevivientes que habían logrado un sólido respaldo crediticio de instituciones financieras de Londres, París, Hamburgo y Nueva York. En estas circunstancias se produjo un intercambio: el Estado solicitaba préstamos al sector privado local para satisfacer sus necesidades básicas, y a cambio permitía la realización de políticas liberales en ma- 
teria financiera, mismas que eran controladas por los bancos locales: "Así el sector privado se afianzó sobre la economía y las finanzas por encima del control estatal". 31

El sector financiero expandido ${ }^{32}$ fue exitoso en la intermediación entre el sector comercial y los sectores de bienes raíces urbanos y el manufacturero incipiente. Los oligopolios que se formaron entonces tuvieron como principal objetivo proteger las ganancias obtenidas en la manufactura, los servicios públicos, las inversiones urbanas y en la recolección de impuestos concedida por el Estado. Hacia 1900, un sector de la elite ya había logrado una mínima autonomía financiera. Por otra parte, se construyeron los ferrocarriles $\mathrm{y}$ las instalaciones portuarias del $\mathrm{Ca}$. llao; se inauguró el transporte oceánico; se impulsó la minería del cobre, el comercio y la manufactura de algodón, así como la importación de trigo y la molienda de harina. En otro rubro, se apoyó el crédito hipotecario. Las primeras fábricas de Lima respondían a dichas tendencias y a la aparición de los primeros grupos económicos nativos. Como apunta Quiroz, existió un proceso de toma de conciencia por parte de un sector de las elites peruanas sobre la necesidad de mejorar los métodos empresariales. ${ }^{33}$

${ }^{31}$ Quiroz, Banqueros, 1990, p. 302.

${ }^{32}$ La expansión del sector financiero se expresa en hechos como la fundación del Banco Italiano en 1899, de la Compañía de Seguros Rímac y de la Internacional de Seguros del Perú en 1894, del Banco Internacional del Perú y de la Compañía de Seguros Italia en 1896, y del Banco Popular del Perú en 1899.

${ }^{33}$ Quiroz, Banqueros, 1990, p. 302.
En la sierra central, luego de años de litigios, las familias notables peruanas recabaron sustanciosos ingresos de corporaciones extranjeras. Auspiciados por este contexto, adquirieron importancia los abogados (para la firma y legalización de los contratos), quienes se enriquecieron y llegaron a ser partes integradas de las instituciones financieras.

No obstante, las estrategias económicas seguidas por las clases propietarias no fueron similares. Básicamente fueron cuatro los caminos elegidos. El primero fue la permanencia de una economía rentista y tradicional, como fue el caso de la familia Riva Agüero. El segundo fue el que siguió un grupo tradicional de la costa, la familia Aspíllaga, que diversificó sus inversiones del azúcar a la minería, los bienes raíces urbanos y las instituciones financieras, los valores y las actividades políticas. El tercero fue el seguido por la familia Miró Quesada: del comercio y la política llegó a la industria de la publicación con el diario de más prosapia en el Perú, El Comercio. El cuarto fue el de ciertos grupos de inversionistas consolidados, que diversificaron sus intereses inclusive hacia la industria, como los Pardo, Prado, Leguía, Olavegoya, Larco, Ayulo y Echenique.

Una expresión de la diversificación de los grupos empresariales es que los bancos de Lima financiaron a numerosos sectores, como las industrias de textiles, sombreros y fósforos, los servicios eléctricos y las empresas de agua; también a las asociaciones agrícolas en Ica, a los productores de cocaína, a los comerciantes chinos, a los ganaderos y grupos de inversión. Los bancos más 
grandes de la época eran el Banco Callao/Perú-Londres (que se acercó a los grupos de exportación), y el Banco Italiano, ligado al abastecimiento del mercado interno. La importancia de este último no es casual, puesto que la comunidad italiana logró los resultados económicos más importantes, siendo exitosa en comercio, banca, construcción, industria y agricultura para el mercado interno, además de formar una red de crédito para pequeños y medianos productores. Por todo lo anterior:

la riqueza del guano, $\tan$ satanizada, habría servido para irrigar la costa, echando las bases de una economía de exportación. El nuevo reino será el de la banca y el dinero, del capital local y el internacional. ${ }^{34}$

En resumen, la guerra del Pacífico fue un parteaguas que permitió visualizar todas las dificultades que arrastraba el Estado peruano para poder formarse como tal: la imposibilidad de que los grupos más consolidados económicamente se convirtieran en una clase hegemónica o predominante, la precaria delimitación de los linderos físico-geográficos dentro de los cuales se podía identificar a un país, la frágil existencia de la soberanía "nacional", y los conflictos irreconciliables entre los distintos sectores de la población peruana que revelaban un débil sentimiento de comunidad.

${ }^{34}$ Neira, Hacia, 1996, p. 365.
LAS MONTONERAS DE 1894 Y EL INICIO DE LA REPÚBLICA OLIGÁRQUICA

Ante el proyecto de Cáceres de perpetuarse en el poder, se formó la Coalición Nacional en 1894 integrada por el Partido Demócrata y la Unión Cívica, ${ }^{35}$ y apoyada por los civilistas. ${ }^{36}$ Éstos, ya repuestos de la crisis de posguerra, se aliaron con Piérola, su otrora gran enemigo, quien organizó las famosas montoneras ${ }^{37}$ y derrocó al héroe de La Breña y a sus aliados (las oligarquías provinciales), acabando con el segundo militarismo. Es el inicio de lo que se conoce en la historia peruana como la "república aristocrática" ${ }^{38}$ (1895-1919),

${ }^{35}$ El Partido Demócrata fue fundado en 1884 por el gran caudillo decimonónico del Perú, Nicolás de Piérola, y la Unión Cívica en 1892 por Mariano Nicolás Valcárcel, notable político del siglo XIX.

${ }^{36} \mathrm{La}$ Coalición Nacional se constituyó luego de la muerte del presidente Remigio Morales Bermúdez (una especie de sucedáneo del gobierno del general Cáceres) en 1894. El momento exigía la convocatoria a nuevas elecciones. Luego de algunas trampas legales, Cáceres asumió nuevamente el control del gobierno. El 30 de marzo de 1894, los partidos Unión Cívica de Mariano Nicolás Valcárcel y el Demócrata de Piérola firmaron un acuerdo fundando la Coalición, y nombrando como jefe a Piérola, quien se encontraba exiliado en Chile. El segundo gobierno de Cáceres sólo duró seis meses (de sep. tiembre de 1894 a marzo de 1895), luego de que Piérola consiguió ingresar a territorio peruano y dirigió exitosamente a las famosas montoneras. El 17 de marzo Piérola ingresó a Lima y Cáceres renunció a la presidencia.

${ }^{37}$ En Huánuco, Piura, Cañete, Lima, entre otras.

${ }^{38}$ Este término, acuñado por Jorge Basadre, tuvo gran aceptación en la historiografia peruana. Sin embargo, últimamente ha empezado a ser cuestionado. Carlos Franco, Hugo Neira, Alicia del Águila y Margarita Guerra Martinière, 
la época de mayor estabilidad institucional y crecimiento económico de la oligarquía peruana. Como señala Hugo Neira, se trata de la "Pax Piérola", conseguida gracias a la prosperidad proveniente de la época guanera y expandida a otros sectores de la economía.

En 1895, la elección de Piérola como presidente del Perú significó un trastocamiento general de la política económica: revaluación del circulante y paulatina adopción del patrón oro, impuestos a la importación, pero libertad de los derechos de importación para la maquinaria. Piérola también promovió la centralización del poder y la autoridad del Estado. Derogó la contribución personal a fin de extinguir las Juntas Departamentales creadas por Cáceres, cortándoles sus fuentes de ingresos. Pero en 1896 creó el impuesto a la sal, que era la restitución solapada del tributo indígena controlado por el Estado. La consecuencia que produjo esta medida fueron las múltiples rebeliones indígenas que se registraron en los primeros años del siglo Xx.

Entre 1895 y 1900 se llevaron a cabo intensas políticas proteccionistas. Comerciantes y banqueros invirtieron en fábricas privilegiadas gracias al am-

entre otros, sostienen que, en sentido estricto, no existía una aristocracia. Por ello, se preferirá llamar al periodo comprendido entre los años 1894 y 1919, república de notables u oligárquica, simplemente. Margarita Guerra resume estas posiciones: "no creemos que haya existido una fracción que pudiera válidamente ostentar tal título, tanto porque los escudos nobiliarios habían quedado atrás, cuanto porque quienes iban a llegar al poder carecian de las calidades de supremacía moral, posición económica y social como para poder reclamar esos títulos [...]". Guerra Martinière, Historia, 1994. paro que les proveía el Estado, que les redituaban altas tasas de ganancias. Las principales industrias protegidas eran las de procesamiento de harina y pastas, textiles (algodón y lana), fósforos, cerveza, cigarros, jabón, velas y sombreros. Dichos sectores estaban bajo el control oligopólico y contaban con un gran respaldo financiero institucional. Entre 1901 y 1902, cuando se desató una crisis del azúcar, la crítica liberal a las medidas proteccionistas encontró un terreno favorable para cobrar audiencia. Además, los exportadores, los mineros y los productores de azúcar se opusieron a los impuestos, dado que preferían un Estado barato. Las instituciones financieras, a su vez, apoyaron la modernización, además de ser receptoras de fondos rentistas. Hasta antes de 1914, estas instituciones sólo habían contribuido mediante el crédito a la formación de asociaciones, cárteles y oligopolios.

El Estado que se construyó sobre estas bases económicas siguió siendo muy débil, con escaso aparato administrativo (en 1900 sólo existían 500 empleados en Lima) y limitadamente centralizado. El Estado oligárquico fue altamente privatizado. De manera gráfica, Manuel Burga y Alberto Flores Galindo señalan, refiriéndose a los hacendados que controlaban el poder político, que "los linderos de sus haciendas eran también los límites de su poder". Incluso, los grandes hacendados se constituían en dueños de caminos, impartían justicia dentro de sus propiedades y ejercían un control severo y paternal sobre las poblaciones indigenas que tenían bajo su mando (pues al mismo tiempo que enviaban al cepo al 


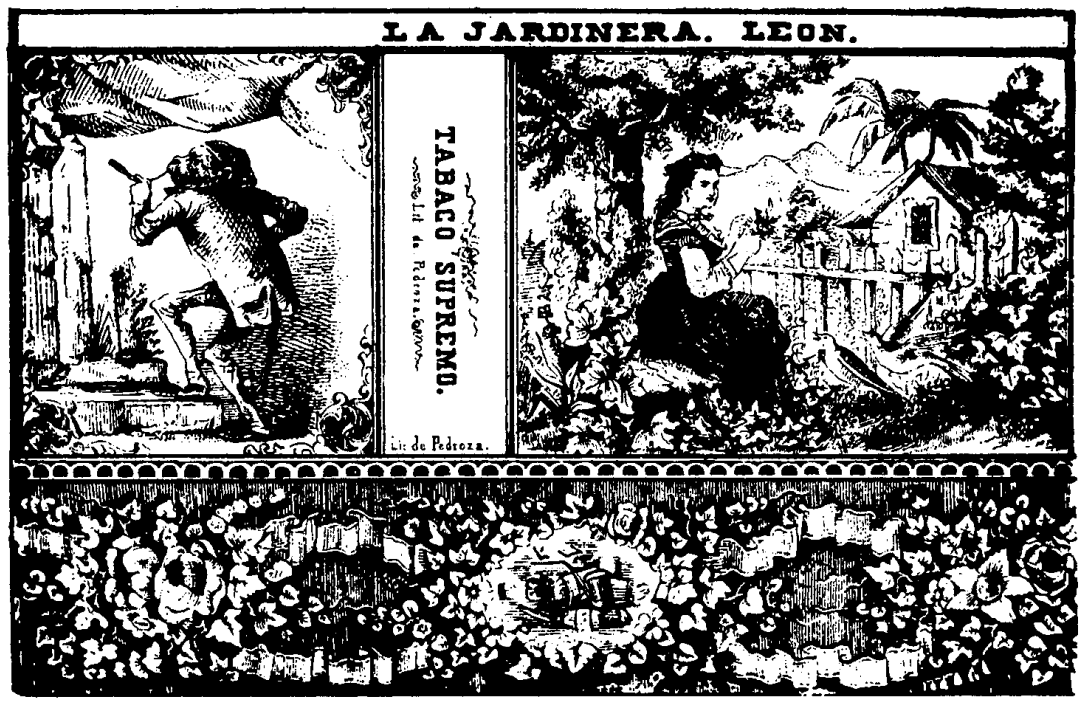

levantisco, podían ser padrinos de los hijos de "sus" trabajadores).

En resumen, las elites oligárquicas se constituían como un grupo social privilegiado que buscaba dejar explícitas sus diferencias con el resto de la sociedad, compuesta por razas consideradas biológicamente inferiores. ${ }^{39}$ Bajo este contexto, construir un Estado y una sociedad nacionales era un proyecto todavía muy lejano de concretar. En resumen, el poder de los hacendados apenas dio forma a un pre-

${ }^{39}$ Es a esto a lo que Gonzalo Portocarrero denomina como aristocracia: "un grupo que reivindica para sus miembros alguna clase de superioridad sobre la cual se legitima la expectativa de derechos especiales y privilegios". Portocarrero, "Fundamento", 1995, p. 219. cario Estado peruano durante los primeros años del siglo Xx.

\section{DISCUSIÓN SOBRE EL ESTADO OLIGÁRQUICO}

El carácter del Estado iniciado en 1894 . 1895 ha sido objeto de múltiples interpretaciones en las ciencias sociales peruanas. El autor del texto más representativo es el artículo de Sinesio López, "El Estado oligárquico: un ensayo de interpretación", de 1978.

Para López, el Estado oligárquico, en tanto organización del poder característica de los estados semicoloniales (o periféricos), debe ser analizado en tres niveles. Económicamente, la base del Estado oligárquico residía tanto en 
la sobrexplotación de la fuerza de trabajo y en la apropiación diferencial de la renta para desarrollar la economía capitalista, como en el estímulo a la apropiación de la renta absoluta de los gamonales. ${ }^{40}$ Políticamente, su poder "se funda exclusivamente en la violencia institucional", la que se ejercía sobre una "masa indiferenciada de clase", produciéndose un consenso pasivo. Socialmente, estaba conformado por un bloque dominante integrado por la oligarquía, los gamonales y el imperialismo. Su dominio se sostenía en la explotación de un proletariado poco numeroso y disperso, y en el bloqueo a las aspiraciones de movilidad social de las clases medias.

Reconociendo la importante aportación de López para la comprensión del Estado oligárquico, es oportuno ofrecer algunos comentarios críticos que permitan seguir la argumentación que expongo en los capítulos siguientes, tomando como referencia, además, un texto reciente del mismo autor. ${ }^{41}$ En primer lugar, ies posible afirmar, como lo hace López, que el Estado oligárquico se fundaba exclusivamente en la "fuerza institucional"? En sentido weberiano, ello supondría reconocer a tal Estado el monopolio legítimo de la fuerza, lo cual es difícil de sostener cuando sabemos del carácter sumamente privatizado del mismo, donde hacendados y poderes locales podían ser dueños "de hombres y tierras" en el interior de sus propiedades. En otras palabras, el Estado oligárquico no estaba conformado como una institución

\footnotetext{
${ }^{40}$ López, "Estado", 1990, p. 37.
}

${ }^{41}$ López, Ciudadanos, 1997. plenamente moderna para poder reconocerle el uso legítimo de la coerción. ${ }^{42}$

En segundo lugar, y de modo complementario, ¿es cierto que el Estado oligárquico sólo se basaba en la coacción física? Burga y Flores Galindo ya han señalado la importancia de cierta visión del mundo, de cierta mentalidad producida por las elites oligárquicas que presentaba como natural la resignación y la división entre afortunados y desdichados. Por otro lado, en el interior de las haciendas también se reproducía cierta cultura, animada por curas y maestros, que propalaban la convicción de que era mejor no alterar el orden de cosas. En otras palabras, existía cierta capacidad de aceptación del statu quo, aun cuando no se produjera una ideología plenamente articulada por parte de las elites oligárquicas. ${ }^{43}$

En tercer lugar, hablar de masas indiferenciadas de clase es cierto a medias, pues las clases trabajadoras de entonces ya comenzaban a exhibir cierta

\footnotetext{
${ }^{42}$ Luego, el mismo López admite tácitamente que fue excesiva su afirmación. Si bien señala que durante 1895-1919 el orden político estuvo por primera vez en manos de una elite que im. pulsó algunas instituciones estatales (como el ejército, por ejemplo), reconoce que el "Estado oligárquico no tuvo el monopolio de la violencia como todo Estado moderno" (ibid., p. 132), sino que éste estuvo en manos de los gamonales. Sólo después de Leguía (1919-1930) se avanzaría en el monopolio de la violencia y centralización de la autoridad, afirma.

${ }^{43}$ López también incorpora en su nuevo análisis la importancia de la mentalidad oligárquica que analizaron Burga y Flores Galindo. Hay que anotar, en descargo de López, que el libro de estos autores fue posterior a su ensayo, el cual, además, fue uno de los textos básicos que utilizaron aquéllos.
} 
conciencia y capacidad de organización que se traducían en una presión sobre el Estado y las elites para la conquista de ciertas reivindicaciones laborales, como lo ha señalado Peter Blanchard ${ }^{44}$ Esta capacidad de los trabajadores debió repercutir necesariamente en las esferas institucionales, cuyas elites para mantener el orden tuvieron que adoptar medidas no "exclusivamente" de carácter represor. En el mismo sentido, tampoco es exacto hablar justamente de un "consenso pasivo", porque impide explicar las múltiples manifestaciones de descontento tanto en el campo como en la ciudad.

En cuarto lugar, al definir el bloque dominante, López señala a la oligarquía como uno de los tres sectores (junto con los gamonales y el imperialismo). El problema que se encuentra en esta definición es que el autor está identificando a la oligarquía únicamente con los hacendados agroexportadores, perdiendo de vista que, en sentido amplio, aquélla es mucho más que ellos. Por eso, en este trabajo me refiero a las elites oligárquicas. Por otro lado, López ubica junto a la oligarquía (agroexportadores) y a los gamonales, al imperialismo. ¿Es correcto decir que el imperialismo era parte del bloque dominante oligárquico? Quizás esta referencia se explique en López por lo que él mismo había señalado: que el Estado oligárquico es la organización política

\footnotetext{
44 "By forming organizations, participating in the nation's political life, and engaging in industrial agitation, they revealed a growing class consciouness and an ability to compel both employers and governments to respond to their demands". Blanchard, Origins, 1982, p. Xv.
}

propia de los Estados semicoloniales. Pero aun así, la dependencia económica del país no supone considerar al imperialismo como parte del bloque dominante. ${ }^{45}$ Este sesgo será corregido por Henry Pease García ${ }^{46}$ cuando señalé que el bloque dominante oligárquico lo constituyen agroexportadores, gamonales y financieros. El excesivo peso que le otorga López a la injerencia política del imperialismo impide reconocer los grados de autonomía de las elites oligárquicas en la toma de decisiones.

Para concluir este artículo, en diversos trabajos sobre el Estado oligárquico, incluido el de López, predomina una visión muy estática del mismo, precisamente por el supuesto dominio monolítico de la oligarquía y por la falta de concientización de las clases subalternas consideradas incapaces de cuestionar el orden. En todo caso, la llamada república aristocrática (con los reparos que conlleva el término) es leída sólo como el momento previo de la sociedad de masas que se revelará en los años treinta. Sin embargo, fue una

${ }^{45}$ En Ciudadanos, López matiza en algo su afirmación cuando señala que la "coalición dominante" (abandona el término "bloque"), estaba compuesta por la oligarquía criolla y gamonalismo (los mestizos) en alianza con el capital extranjero, lo cual permite construir sólo una soberanía limitada. Se advierte la incorporación del indispensable factor étnico-cultural, pero además la relación de la oligarquía y los gamonales con el imperialismo se suaviza al hablar de una "alianza" con éste (ahora utilizando el término "capital extranjero"). De esta manera, subsana en alguna medida la rigidez de la afirmación anterior (de 1978), en la cual el imperialismo era parte del bloque en el poder.

46 Pease García, Ocaso, 1977. 


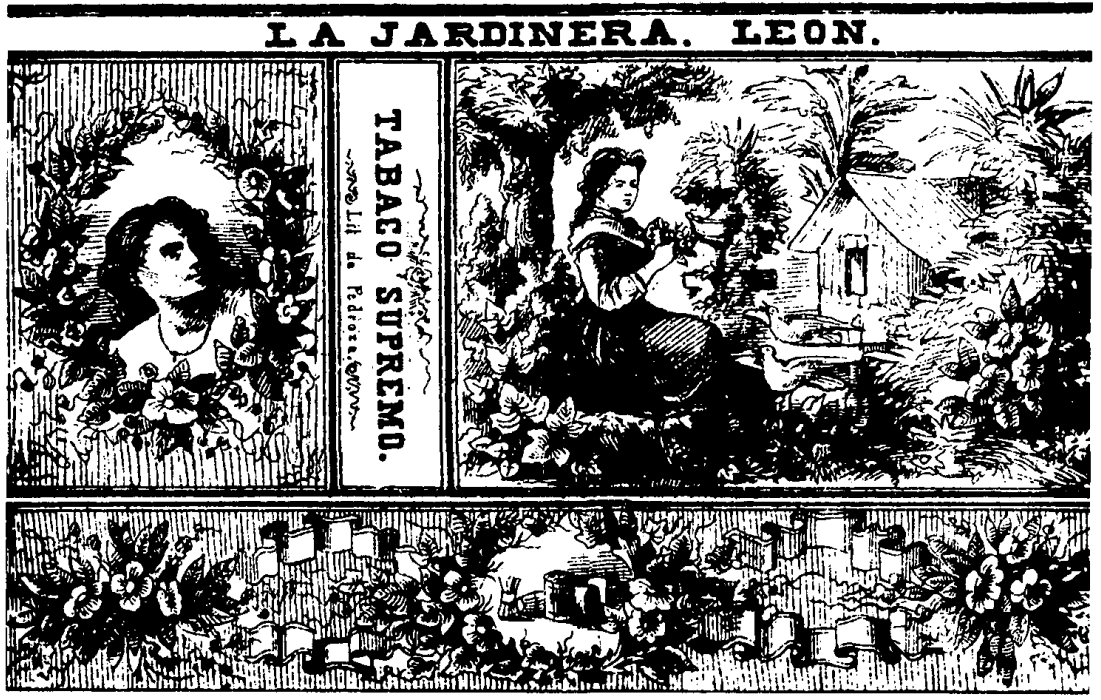

sociedad sumamente contradictoria y dinámica. Como señala Alberto Adrianzén, la oligárquica "es una sociedad en la cual el conflicto social es permanente, donde todo se comienza a mover y donde todo, particularmente en la ciudad de Lima, es lo contrario a la quietud". ${ }^{47}$

\section{BiBliografía}

-Adrianzén, Alberto, "Estado y sociedad: señores, masas y ciudadanos" en Juan Abugattas et al., Estado y sociedad: relaciones peligrosas, Desco, Lima, 1990.

-Basadre, Jorge, El azar en la bistoria y sus limites, PL Villanueva, Lima, 1973.

${ }^{47}$ Adrianzén, "Estado", 1990, p. 19.
Perú: problema y posibili dad [1931], Banco Internacional del Perú, Lima, 1978.

-Belaúnde, Víctor Andrés, La crisis presente [1914], Luis Alfredo Ediciones, Lima, 1994.

-Blanchard, Peter, The origins of the peruvian labor movement, 1883-1919, University of Pittsburgh Press, Pittsburgh, Pa., 1982.

-Bonilla, Heraclio, "Estado y tributo campesino. La experiencia de Ayacucho", Documento de Trabajo núm. 30, IEP, Lima, 1989.

- y Karen Spalding, La independencia en el Perú: las palabras y los bechos, IEP, Lima, 1971.

-Cotler, Julio, Clases, Estado y nación en el Perú, IEP, Lima, 1978.

-Chirinos Soto, Enrique, Historia de la república. Perú 1821-1878, Editorial An. dina, Lima, 1977. 
-Foreman-Peck, James, Historia económica mundial. Relaciones económicas internacionales desde 1850, Prentice Hall, España, 1995.

-Gilbert, Dennis L., La oligarquia peruana: bistoria de tres familias, Editorial Horizonte, Lima, 1982.

-Gonzales, Osmar, Sanchos fracasados. Los arielistas y el pensamiento politico peruano, Ediciones PREAL, Lima, 1996.

-Gootenberg, Paul, "Población y etnicidad en el Perú republicano (siglo XIX). Algunas revisiones", Documento de Trabajo núm. 71, IEP, Lima, octubre de 1995.

, Caudillos y comerciantes. La formación económica del Estado peruano, 1820-1860, Centro de Estudios Regionales Andinos Bartolomé de Las Casas, Cuzco, Perú, 1997.

-Guerra Martinière, Margarita, Historia general del Perú. La República 1900-1948, Editorial Brasa, Lima, 1994, t. ViII.

-López Jiménez, Sinesio, "El Estado oligárquico: un ensayo de interpretación" en El Dios mortal, IDS, Lima, 1990.

- Ciudadanos reales e imaginarios. Concepciones, desarrollo y mapas de la ciudadanía en el Perú, IDS, Lima, 1997.

-Mallon, Florencia, "Problema nacional y lucha de clases en la guerra del Pacífico. La resistencia de La Breña en la sierra central, 1881-1886", Allpanchis, IPA, núms. 1718, 1981, Cuzco.

-Manrique, Nelson, Historia de la república, Cofide, Lima, 1995.

-Neira, Hugo, Hacia la tercera mitad. Perú XT-XX. Ensayos de relectura berética, SIDEA, Lima, 1996.
-O'Phelan, Scarlett, "El mito de la independencia concedida: los programas políticos del siglo XVIII y del temprano XIX en el Perú y Alto Perú" en Independencia y revolución. 1780-1840, INC, Lima, 1987.

-Pease García, Henry, El ocaso del poder oligárquico, Desco, Lima, 1977.

-Portocarrero Maisch, Gonzalo, "El fundamento invisible. Función y lugar de las ideas racistas en la República Aristocrática" en Mundos interiores. Lima 1850-1950, CIUP, Lima, 1995.

-Quiroz, Alfonso W., "Grupos económicos y decisiones financieras en el Perú, 1884-1930", Apuntes. Revista de Ciencias Sociales, Centro de Investigación de la Universidad del Pacífico, núm. 19, 20. semestre de 1986, Lima.

- La deuda defraudada. Consolidación de 1850 y dominio económico en el Perú, Nuevo Mundo, Lima, 1987.

tructura financiera Banques en conflicto. Es1884-1930, CIUP, Lima, 1990.

-Remy, María Isabel, "Historia y discurso social. El debate de la identidad nacional" en Julio Cotler (comp.), Perí 1964-1994. Economia, sociedad y politica, IEP, Lima, 1995.

-Soto, Hernando de, et al., El otro sendero, Editorial El Barranco, Lima, 1986.

-Thurner, Mark, From two republics to one divided. Contradictions of postcolonial nationmaking in Andean Peru, Duke University Press, Durham y Londres, 1977.

-Whitehead, Laurence, "Algunas reflexiones sobre el 'Estado' y el sector informal", Páginas, vol. XV, núm. 101, 1990, Lima. 
Cuadro 1. Ingresos del Estado durante la edad del guano (miles de pesos)

$\begin{array}{lrrrrr}\text { Año } & \text { Aduana } & \text { Guano } & \text { Préstamos } & \text { Otros ingresos } & \text { Total } \\ 1846 & 1608 & 513 & - & 3992 & 6113 \\ 1847 & 2006 & - & - & 2999 & 5005 \\ 1851 & 2225 & 2194 & - & 3218 & 7636 \\ 1852 & 3112 & 3295 & - & 2292 & 8699 \\ 1861^{\mathrm{a}} & 3252 & 16922 & - & 1072 & 21246 \\ 1862 & 3257 & 13985 & 1198 & 1510 & 19949 \\ 1863 & 351 & 11167 & 9830 & 1727 & 26235 \\ 1865^{\mathrm{a}} & - & - & 10000 & - & -20 \\ 1866 & 3904 & 13566 & - & 2658 & 20128 \\ 1868 & 3525 & 21256 & 5574 & 2015 & 3237 \\ 1869 & 4659 & 15288 & 17681 & 4608 & 42236 \\ 1870^{\mathrm{a}} & - & - & 1192 & & \\ 1871 & 6213 & 42716 & 15000^{\mathrm{a}} & & \\ & & & 36800^{\mathrm{b}} & 2252 & 51181 \\ 1872 & 7416 & 34566 & 21167 & 4839 & 67987 \\ 1873 & 8263 & 50026 & - & 2485 & 6771 \\ 1876 & 5542 & 25364 & 8306 & 5034 & 44246 \\ 1877 & 6885 & 6545 & 1178 & 7892 & 22500\end{array}$

a Manrique, Historia, 1995, pp. 121-122.

b En sólo cinco meses.

FUENTE: Bonilla, Guano, 1984, p. 129. 


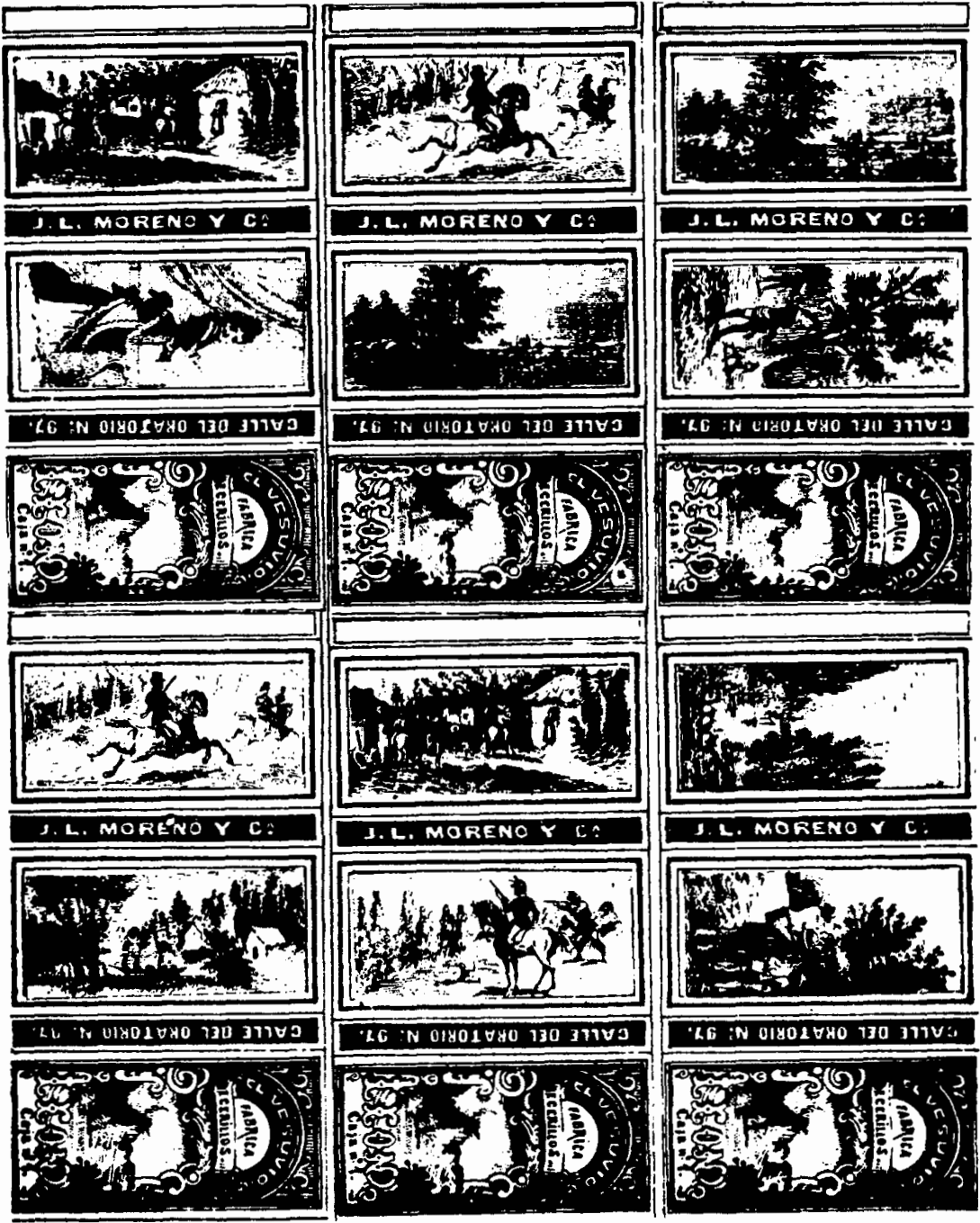

